\title{
Crystalline Growth of Wurtzite GAN on (111) GaAs
}

\author{
J. Ross,* M. Rubin,** and T.K. Gustafson* \\ * Department of Electrical Engineering \\ University of California \\ and \\ **Energy and Environment Division \\ Lawrence Berkeley Laboratory \\ University of California \\ Berkeley, California 94720
}

December 1991

This work was supported in part by the National Science Foundation under Contract No. 1-442427-21482, a Rock.well International Fellowship, and the U.S. Department of Energy under Contract No. DE-AC03. 76.SF00098.

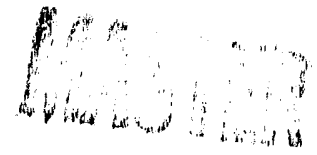




\section{CRXSTALLINE GROWTH OF WURTZITE GAN ON (111) GaAs}

\section{J. ROSS*, M. RUBIN** AND T.K. GUSTAFSON*}

*University of Califomia, Department of Electrical Engineering, Berkeley, CA 94720

**Lawrence Berkeley Laboratory, Berkeley, CA 94720

\section{ABSTRACT}

Gallium Nitride films were grown on (111) Gallium Arsenide substrates using reactiv If magnetron sputtering. Despite a 20\% lattice mismatch and different crystal structure, wurtzite GaN films grew epitaxially in basal orientation on (111) GaAs substrates. Heteroepitaxy was observed for growth temperatures between $550-600^{\circ} \mathrm{C}$. X-ray diffraction patterns revealed (0002) GaN peak with a full-width-half-maximum (FWHM) as narrow as $0.17^{\circ}$. Possible surface reconstructions to explair the epitaxial growth are presented.

\section{INTRODUCTION}

Gallium Nitride is a direct wide bandgap semiconductor $(3.4 \mathrm{eV})$ having potential applications for stimulated emission in the blue, violet, and vitra-violet spectral range. Development of GaN devices have been limited by nroblems in obtaining p-type conduction and convenient substrates for epitaxial growth. Recent reports of p-type conduction $[1,2]$ in $\mathrm{Mg}$ doped sampler, show promise in this area. As seen in Table I, there are no readily available substrates that are lattice matched to $\mathrm{GaN}$ in both lattice parameter and thermal expansion coefficient. Sapphire has been frequently used despite a $16 \%$ lattice mismatch. Attempts on other substrates include: silicon [3,4], gallium arsenide [3,5,6,7], gallium phosphide [3], and silicon carbide [8]. Aluminum nitride has been used effectively as a thin-film buffer layer on sapphire for improved GaN growth [9]. Table I summarizes the material data for GaN and various substrates. The lattice parameters for the cubic crystals are given as the effective spacing in the (111) plane corresponding to " $a$ " in the wurtzite system for easier comparison.

Table I. Lattice parameters and thermal expansion coefficients of various substrates.

\begin{tabular}{|c|c|c|c|}
\hline Material & $\begin{array}{l}\text { Lattice constant } \\
\text { (A) }\end{array}$ & $\begin{array}{c}\Delta \operatorname{aGaN}_{(\%)} / \Delta \mathrm{a} \text { sub } \\
(\%)\end{array}$ & $\begin{array}{l}\text { Thermal exp. } \\
\text { coef. }\left(\times 10^{-6} / \mathrm{K}\right)\end{array}$ \\
\hline$\overline{\mathrm{GaN}}$ & $\begin{array}{l}a=3.189 \\
c=5.182\end{array}$ & $\cdots$ & $\begin{array}{l}5.6 \\
7.7\end{array}$ \\
\hline AIN & $\begin{array}{l}a=3.111 \\
c=4.980\end{array}$ & $\begin{array}{l}+2.5 \\
\cdots\end{array}$ & $\begin{array}{l}5.3 \\
4.2\end{array}$ \\
\hline$\alpha-\operatorname{SiC}(6 H)$ & $\begin{array}{l}a=3.08 \\
c=15.11\end{array}$ & $\begin{array}{l}+3.4 \\
\cdots-. .\end{array}$ & $\begin{array}{l}4.2 \\
4.8\end{array}$ \\
\hline $\mathrm{Al}_{2} \mathrm{O}_{3}$ & $\begin{array}{l}a=2.74 \\
c=12.991\end{array}$ & $\begin{array}{c}+16.1 \\
\cdots\end{array}$ & $\begin{array}{l}7.5 \\
8.5\end{array}$ \\
\hline GaAs (111) & $a=3.997$ & -20.2 & 4.8 \\
\hline
\end{tabular}


Despite the large mismatch, GaAs is desirable due to its wide acceptance in the electrooptic industry. Few researchers trave used GaAs as a substrate for GaN growth possibly because early comparisons showed sapphire to produce smoother and more oriented GaN films [5]. Recently, the electrical properties of cubic GaN in a S.I-S structure on (100) GaAs grown by modified molecular beam epitaxy has been reported [10]. Corcurrent work in Japan, involving the growth of GaN on (111) GaAs by MBE has also shown wurtzite GaN on (111) GaAs [6], however, our material appears to have narrower (0002) GaN X-ray diffraction peaks. GaN is typically grown by chemical vapor deposition (CVD) or modified molecular beam epitaxy (MMBE). Sputter deposition has produced highly resistive GaN films in the past [11], and although it is perhaps not suitable for the growth of minority carrier elestronic devices, sputter deposition can be a viable method for the study of GaN growth kinetics and rudimentary GaN devices.

In this paper, we report the gro'wth of highly oriented wurtzite GaN films on the (111) face of GaAs. Little strain is observed, but crystalline growth is a sensitive function of temperature. The growth conditions and possible explanations for the heteroepitaxy are detailed. This is the first report of crystalline wurtzite GaN on (111) GaAs by sputter deposition techniques.

\section{EXPERIEMNTAL PROCEDURE}

The GaN films were deposited using an US Gun-II 2 inch modular source. The target was pure gallium $(9.999999 \%)$ held in a siainless steel cup. The GaAs substrates were degreased and etched before deposition in a <111> directional etch of $1 \mathrm{H}_{2} \mathrm{O}: 5 \mathrm{H}_{2} \mathrm{SO}_{4}: 1$. $\mathrm{H}_{2} \mathrm{O}_{2}$ at $65^{\circ} \mathrm{C}$ for 2 minutes. The substrates were then rinsed with alcohol and dried before entering the chamber. The chamber was evacuated to less than 10-7 Torr, and then backfilled with a mixture of $\mathrm{N}_{2}$ and $A r$ gas to 25 inTorr. The substrates were heated to $500-700^{\circ} \mathrm{C}$ as measured by a thermocouple clamped on the surface of the heating block. As soon as the discharge was ignited, the Ga target liquified and slowly formed a nitrided crust. ENI sources were used to deliver 110 watts of of $(13.56 \mathrm{MHz})$ power to the 2 inch target. The growth rate was measured by a quartz-crystal oscillator calibrated with a stylus proi.a.umeter. Growth rates ranged from 1-5 A/s. After deposition, the substrates were 6001 ed to $200^{\circ} \mathrm{C}$ in $100 \%$ nitrogen atmosphere at $30 \mathrm{mT}$ Trr. The choice of deposition parameters for epitaxial growth was partly determined from our earlier work on sapphire substrates $[12,13]$. Higher partial jressures of nitrogen (25 mTorr) were needed to crystallize $\mathrm{GaN}$ on (111) GaAs compared to the sapphire substrates. However, similar nitrogen flow rates $(200 \mathrm{sccm})$ and $\mathrm{N}_{2}: \mathrm{Ar}$ ratios $(7.3)$ were used.

\section{RESULTS AND DISCUSSION}

The GaN film's crystal orientation was analyzed using a Siemens $x$-ray diffractometer (CuK $\alpha, \lambda=0.154 \mathrm{~nm}$ ). For temperarures below $550^{\circ} \mathrm{C}$ only mixed phases of GaN were outained (Figure la). In this temperature range, the films were characterized by rough surfaces with numerous ciefects as seen in Figure $1 \mathrm{~b}$. For growth temperatures between $550.600{ }^{\circ} \mathrm{C}$ 


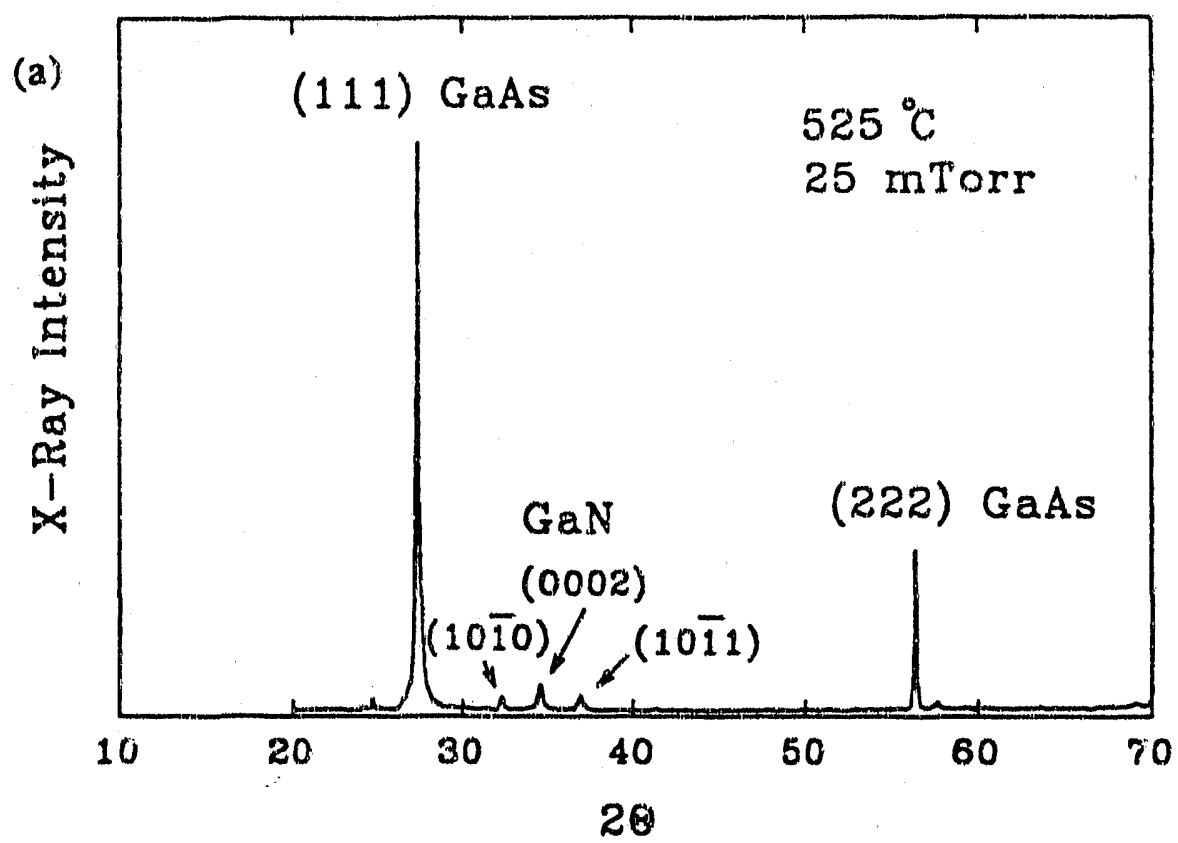

(b)

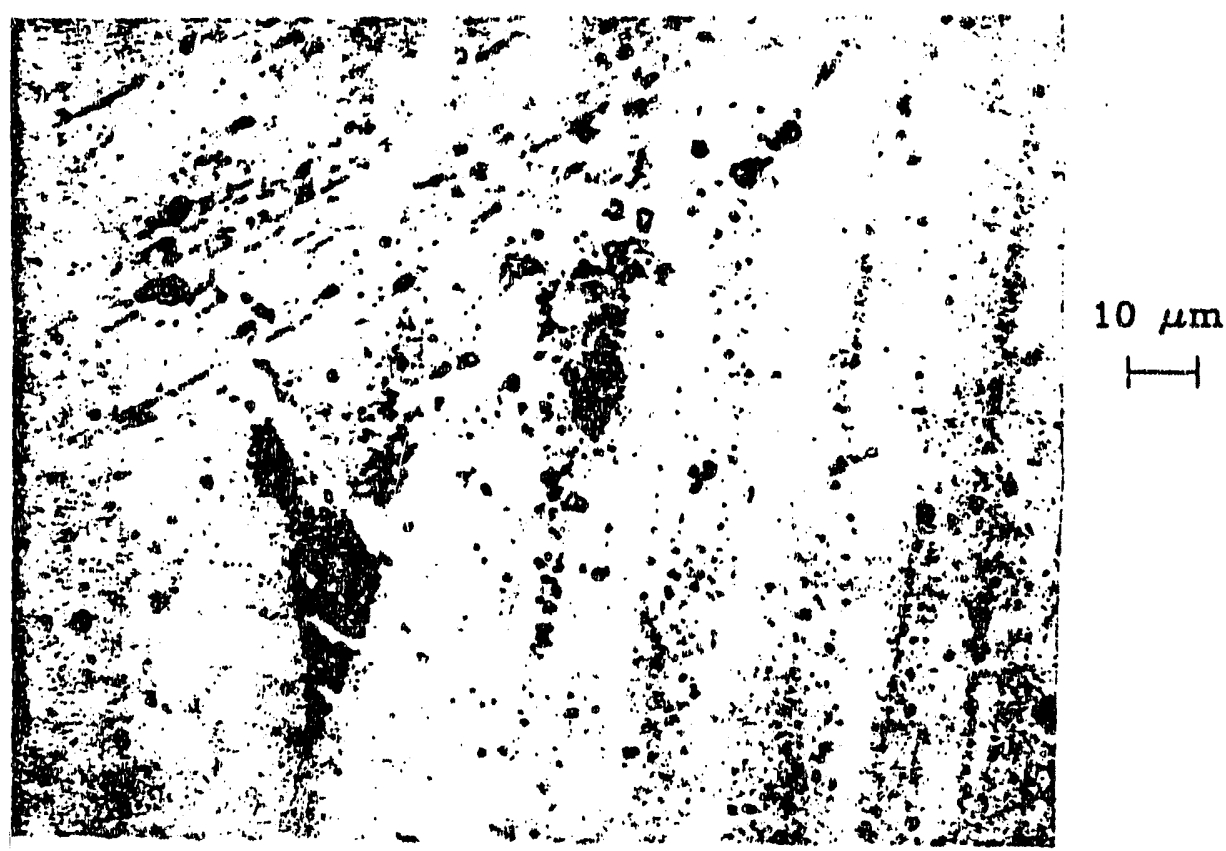

Figure 1(a) X-ray diffraction pattern of GaN film grown at $525^{\circ} \mathrm{C}$; and (b) the surface of the film characterized with many defects.

highly oriented basal plane GaN was achieved with much smoother surface morphology. Figures $2 a$ and $2 b$ show the $x$-ray pattern and the surface morphology of a $200 \mathrm{~nm}$ film grown at $580^{\circ} \mathrm{C}$. The FWHM of the $(0002)$ peak is $0.17^{\circ}$. The peak is located at $2 \theta=34.607^{\circ}$ which corresponds to a d-spacing of $2.589 \mathrm{~A}$. The neasured $(00,32)$ plane spacing is therefore 5.178 $A_{1}$, which agrees weli with the theoretical value of 5.182A. Despite the large lattice mismatch, the $(0002)$ planes do not appear appreciably strained. We did not observe any critical thickness phenomen. For films grown under similar conditions, no variation in peak location or width was measured for film thicknesses ranging from $0.05-2 \mu \mathrm{m}$.

For substrate temperatures greater than $620^{\circ} \mathrm{C}$ the $\mathrm{x}$-ray diffraction peaks vanished and many films delaminated from the GaAs sibstrates. We found the delamination could be 


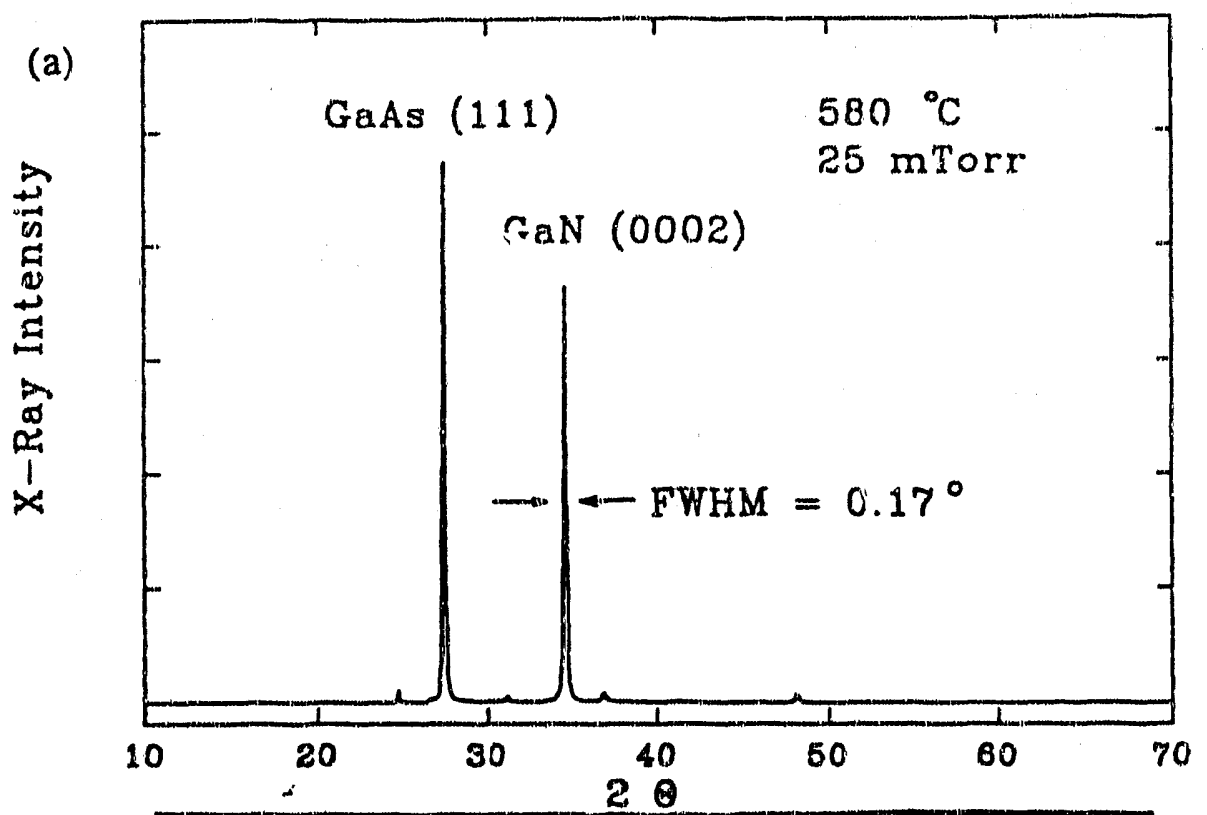

(b)

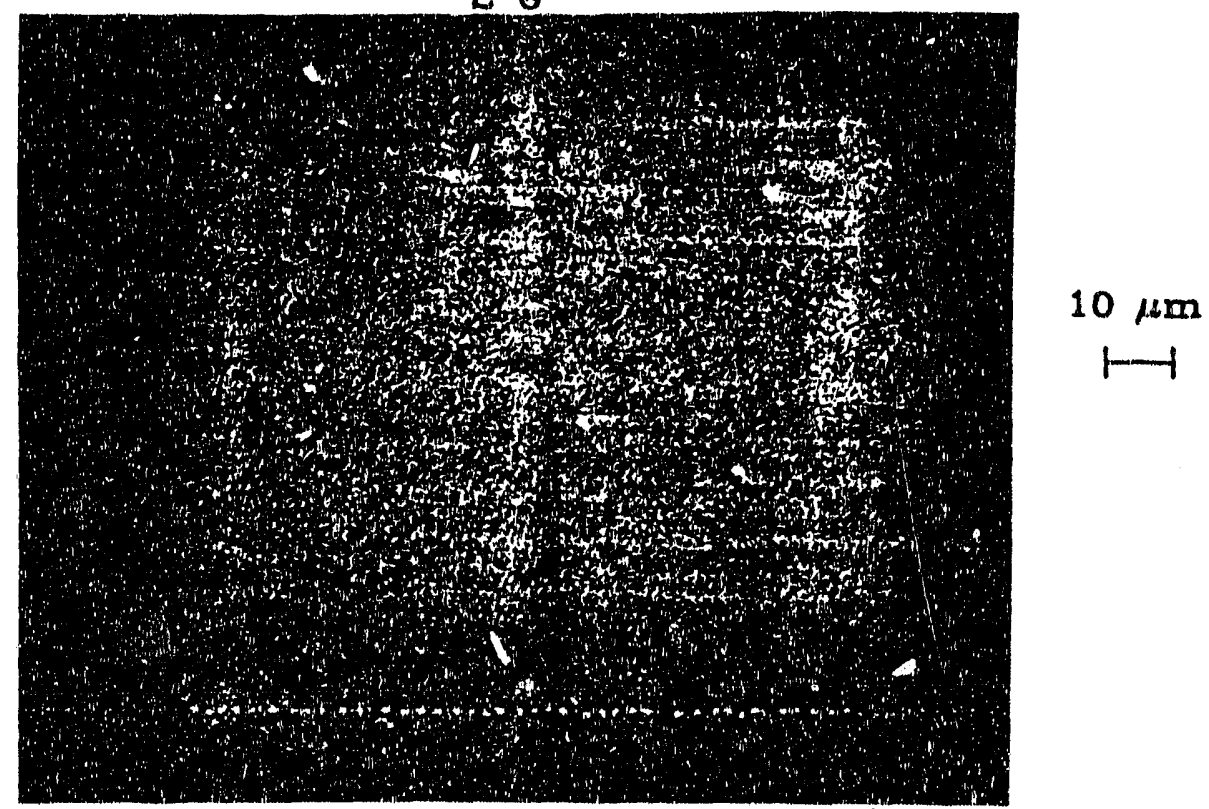

Figure 2(a) X-ray diffracttion pattern of GaN film grown at $580^{\circ} \mathrm{C}$; and (b) the smoother surface morphology of this film.

minimized and in some cases eliminated if the films were cooled down slowly from the growth temperature $\left(\sim 100^{\circ} \mathrm{hr}\right)$. Also, no appreciable GaN $x$-ray peaks were observed at pressures below 20 mTorr. To ensure the $x$-ray diffraction peak at $2 \theta=34.607^{\circ}$ is indeed the (0002) wurtzite phase of GaN and not strained cubic GaN growing in the (111) direction, reflection electron diffraction (RED) was employed. With the beam incident on the (1120) plane, only spots in vertical rows were visible as predicted by theory. Carrier concentrations for these GaN films were all n-type and greater than $2 \times 10^{18} \mathrm{~cm}^{-3}$.

We believe the reason highly oriented wurtzite GaN was obtained on (111) GaAs can be explained by examining the 2-D interface. Figure 3a shows the wurtzite and zinc-blende crystal structures with the $<0002\rangle$ and $<111>$ directions aligned. The only difference between the wurtzite and zinc-blende structures in these directions is the stacking order of the layers. The (111) GaAs face has the identical bond termination as the GaN basal plane substrate would. 
The atomic spacing is the only difference between the (0002) GaN and (111) GaAs planes. These similarities were the reason the (111) face of GaAs was chosen over other orientations. Heteroepitaxy on large mismatch systems has been achieved on other material systems when the number of broken bonds is minimized and the 2-D interface lattices have a common superlattice $[14,15,16]$. The likelihood of epitaxy increases with the number of coincident sites. As seen in Figure 3b, the (0002) GaN and (111) GaAs planes are overlapped. The larger unit cell drawn has a considerably smaller mismatch $(4 \%)$ between the two materials at room temperature.

(a)

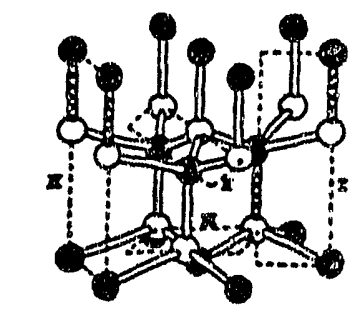

WURZITE

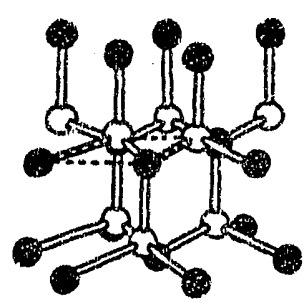

ZINC BLENDE (b)

$\triangle<1 i 1\rangle$ GaAs lattice sito

- :000z> GaN lattice nite

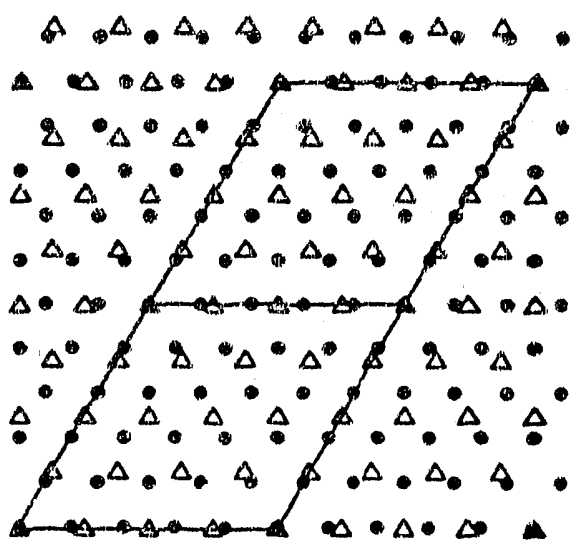

Figure 3(a) Wurtzite and rinc-blende crystal structures oriented with the basal plane and (111) directions aligned; and (b) Overlap of the (111) GaAs and (0002) GaN planes. The larger unit cell represents a $4 \%$ mismatch.

\section{CONCLUSIONS}

In summary, hexagonal GaN has been grown epitaxially in the basal orientation on the (111) face of GaAs using if reactive sputter deposition. Phase identification is verified with $x$ ray diffraction and RED measurements. A narrow temperature regime $\left(550-600^{\circ} \mathrm{C}\right.$ ) is defined which produces highly oriented films with smooth surface morphologies. The differences in the 3-D crytstal structures appear to be less important than the similarities of the 2-D interface for the $(0002) \mathrm{GaN} /(111) \mathrm{GaAs}$ systern.

\section{ACKNOWLEDGEMENTS}

We would like to thank Jeff Walker (UCB) for assistance with the RED measurements. Partial support was provided by the U.S. Department of Energy under contract \# DE-ACO376 SF00098 and the National Science Foundation \# 1-442427-21482. Funding was also provided through a Rockwell International fellowship. 


\section{REFERENCES}

1. H. Amano, M. Kito, K. Hiramatsu and I. Akasaki, Jap. J. Applied Physics, 28, L2.112 (1989).

2. S. Nakamura, M. Senoh and T. Mukai, Jap. J. Applieci Physics, 30, L1708 (1.991).

3. Y. Morimoto, K. Uchiho and S. Ushio, J. Electrochemical Society, 120, 1783 (1973).

4. T. Lei, M. Fanciulli, R. Molnar, T. Moustakas, R. Graham and J. Scanlon, App. Physic: Letters, 52, 944 (1991).

5. B. Kosicki and D. Kahng, J. of Vacuum Science and Tech., 6, 593 (1969).

6. H. Okura, S. Misawa and S. Yoshida, Applied Physics Letters, ⒐ 1058 (1991).

7. M. Mizuta, S. Fujieda, Y. Matsumoto and T. Kawamura, Jap. J. Applied Physics, 25, L945 (1986).

8. T. Sasaki and T. Matsuoka, J. Applied Physics, 64, 4531 (1988).

9. I. Akasaki, H. Amano, Y. Koide, K. Hiramatsu and N. Sawaki, J. Crystal Growth, 28,209 (1989).

10. G. Martin, S. Strite, J. Thorton, H. Morkoc, App. Physics Letters, 58, 2375 (1991).

11. E. Lakshmi, B. Mathur, A. Bhattacharya, and V. Bhargara, Thin Solid Films, 74, 77 (1980).

12. J. Ross, M. Rubin, Materials Letters, accepted July 1991.

13. J. Ross, Masters thesis, University of California Berkeley, 1990.

14. F. LeGoues, M. Liehr, M. Renier and W. Krakow, Philosophical Magazine B, 57, 179 (1988).

15. A. Zur and T. McGill, J. Applied Physics, 55, 378 (1984).

16. P. Bai, G-R. Yang, L. Lou and T-M. Lu, J. Material Research, 5, 989 (1990). 

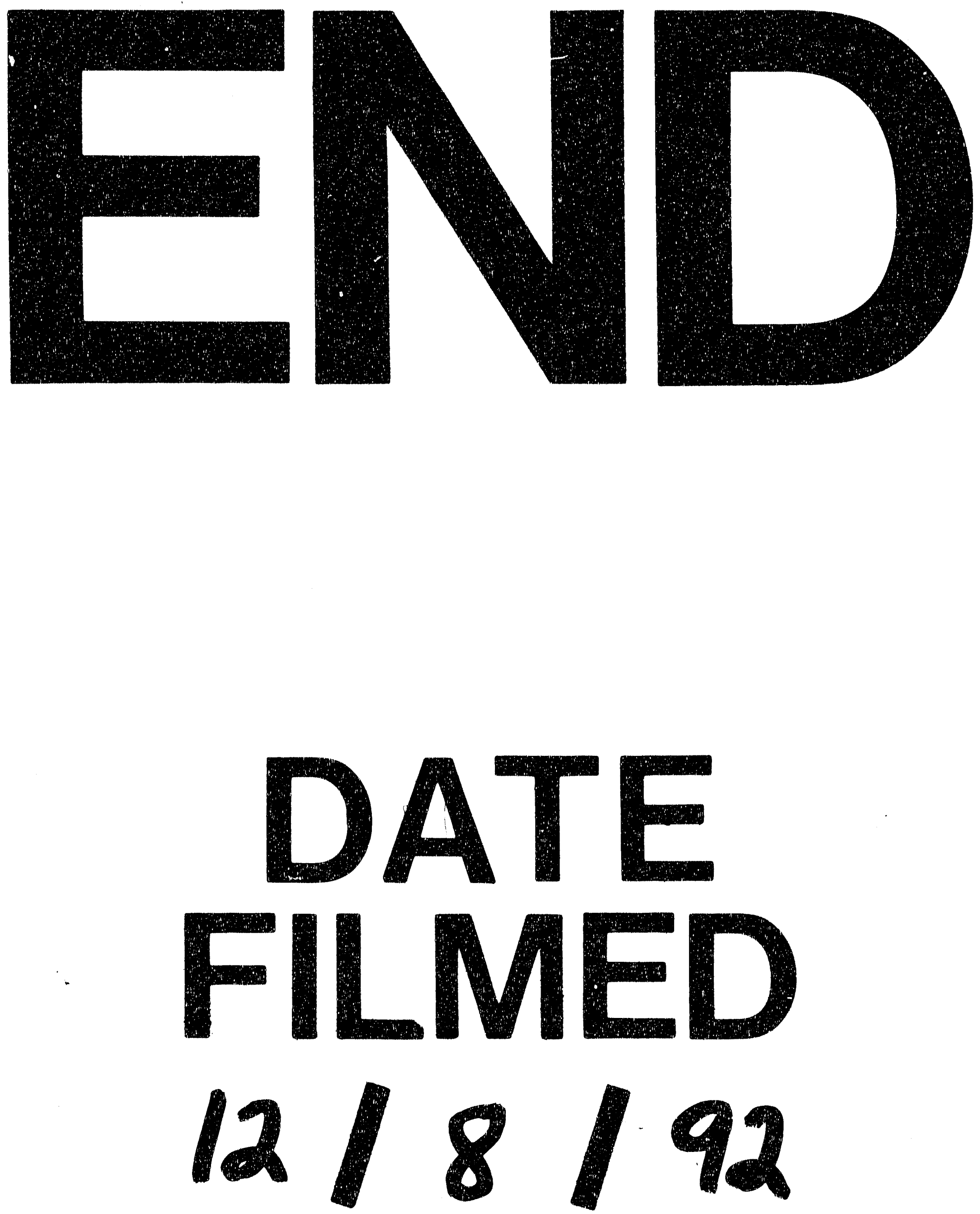
